\title{
A COMPARISON OF COMPONENTS OF WRITTEN EXPRESSION ABILITIES IN LEARNING DISABLED AND NON-LEARNING DISABLED STUDENTS AT THREE GRADE LEVELS
}

\author{
Mary S. Poplin, Richard Gray, \\ Stephen Larsen, Alison Banikowski and Tes Mehring
}

\begin{abstract}
Although written language plays a critical role in academic success, little empirical evidence exists on the normal development of processes involved in producing written products. Even less is known about the writing performance of LD children. This study empirically compared the written products of LD and normal students at three grade levels on The Test of Written Language. Results showed that LD subjects scored significantly lower than normal subjects on most written expression abilities, especially in the mechanical tasks of spelling, punctuation, and word usage.
\end{abstract}

The importance of written language to the success of any student in public schools cannot be overstated. Courses with varying titlesLanguage Arts, English, Rhetoric, Composition-have been the joy or pain of all students who have attempted to endure the educational system designed to make them literate. Still more significant is the fact that, from at least the intermediate grades through college, writing becomes the major means by which students demonstrate their knowledge and the major tool through which teachers evaluate student performance in all content areas. Considering the role of written language in a student's educational well-being, the amount of meaningful, research-based information regarding the nature of normal students' written products and their writing processes is discouraging (Petty, 1978). The works of Hunt (1965, 1966, 1977), Loban (1963, 1966, 1967), and a host of other researchers have increased substantially our descriptive understanding of the syntax and productivity of normal children's written products. Less is known about ideation or the

MARY S. POPLIN, Ph.D., is Assistant Professor, Dept. of Special Education, The University of Kansas.

RICHARD GRAY, Ph.D., is Assistant Professor, Dept. of Special Education, The University of Oklahoma.

STEPHEN LARSEN, Ed.D., is Associate Professor, Dept. of Special Education, The University of Texas, Austin.

ALISON BANIKOWSKI, Ms. Ed., is an Instructor, Dept. of Special Education, The University of Kansas.

TES MEHRING, Ms. Ed., is an Instructor, Dept. of Special Education, The University of Kansas. 
ability to convey thoughts, ideas, and understandings through writing. A growing number of researchers are voicing the concern that the least is known about the processes we go through as we prepare to write, as we write, and as we revise (Petty, 1978; Britton, 1978; Emig, 1978).

The role of written language in school success is even more significant for the learning disabled (LD) child. Lerner (1976) considered poor writing skills to be the most prevalent communicative disability of learning disabled children. In a recent study at the Kansas Research Institute in Learning Disabilities (Research Report \#13), poor written expression ability was determined to be a major characteristic distinguishing learning disabled high school students from their nondisabled peers. The importance of writing to survival and appropriate performance in the regular classroom necessitates that educators of learning disabled students understand the unique needs of their students, especially if integration in the regular classroom is to be the primary goal of remediation and compensation.

Slim indeed is the research describing the differences between normal and learning disabled individuals' writing processes and their writing performance. The work of Myklebust $(1965,1973)$ has been considered the major source of information regarding the written language of the learning disabled and the writing of learning disabled and normal individuals. Using his test, The Picture Story Language Test (PSLT, 1965), designed to "... study the development and disorders of written language" (1973, p. 11), Myklebust reports that learning disabled children received significantly lower scores related to syntax, ideation, total number of words, and words per sentence than their nondisabled peers. At both the moderate and severe disability levels, the highest degree of difference between the learning disabled and nondisabled was related to syntax and to ideation, respectively. Writing samples of the two groups revealed no significant difference in total number of sentences. "Reading disability" children differed significantly from their normal peers in all measures of productivity, syntax, and ideation. "Dyslexic" children differed primarily on productivity measures (total words and total sentences) with only nine-year-olds differing from their peers on words per sentence and nine- and elevenyear-olds differing from their peers on syntax measures. No difference was found on measures of ideation (Myklebust, 1973).

In a more recent study using The Picture Story Language Test, Poteet (1978a) determined that learning disabled students wrote half as many words and sentences as did their nondisabled peers. The learning disabled also made more punctuation errors and omitted more words. Other measures of syntax, conventions, and ideation did not differ significantly.

Hermreck (1979), using The Inventory of Written Expression (Poteet, 1978b), found that learning disabled children in grades 3-6 made significantly more spelling errors than did their nondisabled peers. Although LD subjects were much less productive, made more capitalization and punctuation errors, and wrote less complex and sophisticated syntactic structures than did their nondisabled peers, the differences between the two groups were not reported as statistically significant.

The above works are important as a foundation on which to build an understanding of the writing abilities of the learning disabled. A strength of the studies is that all are based on actual writing samples. Confidence in interpretation of the results is limited, however, because of the tests used. The Picture Story Language Test suffers from reliability and validity problems (Anastasiow, 1972; Hammill \& Bartel, 1978). Also, Poteet (1978a) found that students wrote less in response to the slightly outdated stimulus picture of the PSLT than to updated stimulus pictures. The Inventory of Written Expression, although it appears to be theoretically sound, was designed as an informal diagnostic instrument for which statistical analyses of reliability and validity were not available.

The purpose of this study was to compare empirically the written products of learning disabled and non-learning disabled students at three grade levels using a standardized instrument which is practical for classroom teachers and which has demonstrated reliability and validity. Therefore, comparisons 
were made of the vocabulary, thematic maturity, spelling, punctuation, and word usage components of learning disabled and non-learning disabled students' written expression. The productive component was not examined. This is the first of a series of studies examining the writing performance of learning disabled students in order to determine whether they are, in fact, less able to express themselves in writing than their nondisabled peers and, if so, to understand more fully the writing deficits in order to provide direction for remediation and compensation.

The research questions posed in this study are as follows:

1. Do students identified as learning disabled in grades 3-4, 5-6, and 7-8 differ from their nondisabled peers in their overall ability to express themselves in writing as measured by the Test of Written Language (Hammill \& Larsen, 1978)?

2. Do students identified as learning disabled differ more significantly from their nondisabled peers in any one or a combination of the subtests of vocabulary, thematic maturity, word usage, spelling, and/or punctuation as measured by the Test of Written Language?

\section{Instrumentation}

\section{METHOD}

The Test of Written Language (TOWL) was used to examine the existence and nature of differences between the written expression of learning disabled and non-learning disabled children at three grade levels. The TOWL is a standardized instrument designed to measure the general adequacy of a written product and to determine proficiency in the conceptual, productive, and mechanical components of the written products of individuals from age eight years, six months to fourteen years, five months.

The instrument uses both contrived and spontaneous formats. To elicit actual, spontaneous writing samples from students, three pictures are presented depicting an outerspace related sequence; students are asked to "make up a good story to go with them." The spontaneous product is analyzed for thematic maturity, vocabulary, number of sentences, and handwriting. Contrived tests are used to examine spelling, word usage, and style.
Five major subtests are designed to assess the more conceptual components of written products. Thematic Maturity uses the student's spontaneous writing sample to evaluate the ability to convey meaning according to twenty criterion statements provided in the manual. In the Vocabulary subtest, 25 words are selected randomly from the student's spontaneously written story and assigned a value based on several recognized word-frequency lists. Specific guidelines are provided in the manual for random word selection. The Spelling subtest uses a contrived format. Twenty-five words, selected on the basis of their discriminating power, are pronounced in isolation, used in a sentence, and pronounced again in isolation. Students spell the words on their answer sheet from dictation. The Word Usage subtest uses a contrived, Cloze format to measure the student's ability to form tenses and plurals, to use objective and nominative cases, and to utilize other conventional linguistic features of "informal standard" English. The Style subtest measures mastery of the conventions governing the use of punctuation and capitalization. A contrived format is used requiring the student to read sentences written without any punctuation or capitalization and to rewrite them "correctly". Two supplementary subtests, Handwriting and Thought Units, were not used in this study.

The TOWL yields raw, grade equivalent, and scaled scores for each subtest as well as for the total test. The Written Language Quotient (WLQ) gives an overall index of writing competence similar to the Intelligence Quotient (IQ) with a mean of 100 and a standard deviation of 15 . Subtest scaled scores are based on a mean of 10 and a standard deviation of 3 . The reliability and validity of the TOWL has been adequately established. Using the Kuder-Richardson formula to establish internal consistency, the authors of the TOWL found all coefficients to be statistically significant at the .01 level of confidence. Testretest reliability coefficients were: Vocabulary (.62), Thematic Maturity (.86), Spelling (.96), Word Usage (.85), and Style (.94). Interscorer reliability for the five major subtests was established between .93 and .98. Extensive correlations are provided between the TOWL and 
The Picture Story Language Test at several grades, as well as with mentally retarded and learning disabled populations. Information regarding these and other statistical measures of reliability and validity is provided in the manual (see also Deno, Mirkin, \& Marston, 1980).

\section{Subjects}

This initial investigation of learning disabled and normal students' written expression abilities included 250 students from grades three through eight. All subjects attended suburban school districts outside Austin, Texas, and Kansas City, Kansas, and Kansas City, Missouri. All school districts offered a complete range of special services for exceptional students, including services for the gifted. The students' families were classified as being of middle- to high-middle socioeconomic status. The subject pool was narrowed to 198 subjects by random selection to form equal cells for analyses (99 LD and 99 normal). Ninety-nine of the subjects were normal achievers who had received no special services (including services for gifted) during their schooling. The 99 normal achievers were divided into three groups of 33 each, comprised of students in grades 3-4, 5-6, and 7-8. The remaining 99 subjects had been classified as learning disabled by their school districts and were receiving services accordingly. They all fell within one standard deviation on the WISC-R full-scale intelligence quotient and were underachieving by a minimum of two years on one of several group achievement tests utilized by the various schools (e.g., Iowa, Stanford or SRA achievement tests). These $99 \mathrm{LD}$ subjects were also divided into three groups of 33 subjects each, comprised of students in grades 3-4, 5-6, and 7-8. Mean chronological ages for the LD and normal groups were not found to be significantly different in an analysis of variance $(p=$ .09). However, the mean chronological age of the LD subjects at each of the grade levels was several months younger. Due to this nearsignificant difference, it was decided to hold the age of the groups constant by using $C A$ as a covariable in the subsequent analysis.

\section{Procedures}

Eight certified learning disability specialists (who had been trained in the administration of the TOWL) administered the test to small groups of students who met the established criteria. These same specialists scored each of the tests on the subjects of Vocabulary, Thematic Maturity, Spelling, Word Usage, and Style and computed the Written Language Quotient for their subjects. Scores were not established or analyzed for the two supplementary tests of the TOWL, i.e., Thought Units and Handwriting. One of the authors rechecked the scoring of each test to assure accuracy.

The derived scaled scores for each of the subtests as well as the Written Language Quotients (WLQ) were then subjected to ANOVA with chronological age held constant. The WLQ analysis was performed separately from the analyses of the subtest differences. The $p \leq .01$ level of significance was established for determining differences between LD and normal students' scores.

\section{Results}

The results of the analyses of covariance are depicted in Table 1. At grades 3 and 4 the LD and normal groups were not significantly different $(p>.01)$ on the measures of Vocabulary and Thematic Maturity; however, on measures of Spelling, Word Usage, and Style significant differences $(p \leq .01)$ were found. The two groups at grades 3 and 4 were also significantly different on the total Written Language Quotient. At grades 5 and 6 the learning disabled subjects did not differ significantly from their normal counterparts on Vocabulary. However, on all other measures, i.e., Thematic Maturity, Spelling, Word Usage, Style, and Written Language Quotient, LD students performed significantly more poorly than their normal peers. Similarly, at grades 7 and 8 learning disabled students scored significantly lower than normal 7th- and 8thgrade students on all of the TOWL measures of written language.

Figure 1 depicts the mean results of the learning disabled students' performance at each of the three grade levels in terms of the TOWL standardization data. Interestingly, when the data are viewed in terms of the standard deviations set by the test manual for the individual subtests as well as for the Written Language Quotient, the learning disabled 


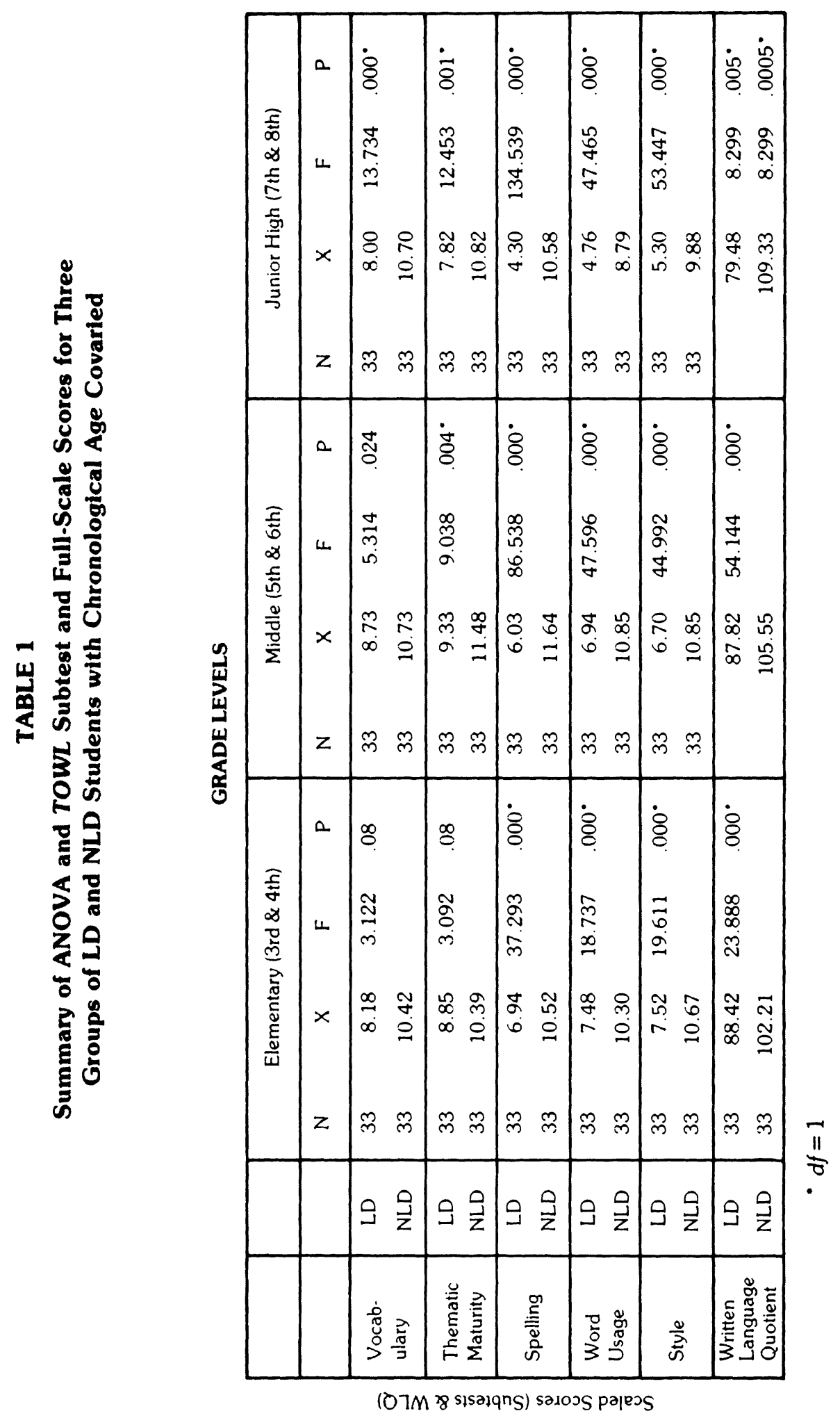




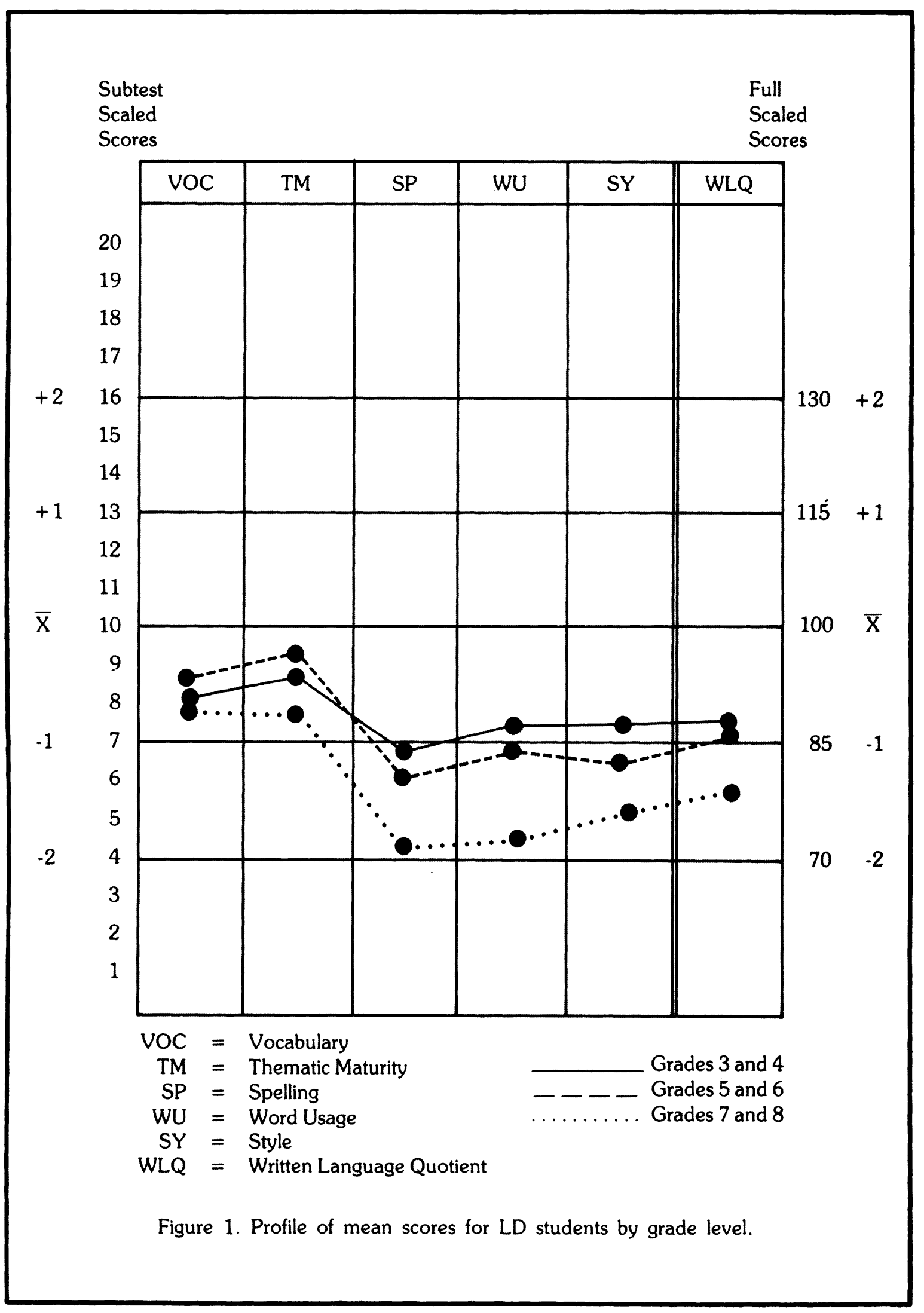


students were found to perform within one standard deviation of the mean in Vocabulary and Thematic Maturity at all grade levels. At no grade level did the learning disabled subjects perform within one standard deviation of the mean in Spelling. Only at grades 3 and 4 did the learning disabled groups perform within one standard deviation of the mean on Word Usage and Style. The learning disabled subjects' Written Language Quotient fell within one standard deviation in grades 3-4 and 5-6 but fell below one standard deviation in grades 7-8. In comparison, by examining Table 1 we find that the mean scores for the normal students in all instances hovered very close to the means established by the TOWL norms.

\section{DISCUSSION}

This study found that 3rd- through 8thgrade learning disabled students scored significantly lower than normal 3rd - 9th graders in written abilities as measured by the Test of Written Language. While some scores of the learning disabled group (particularly at grades 7 and 8) were found to be significantly lower than those of normals in the more conceptual tasks of Vocabulary and Thematic Maturity, these mean scores did not at any grade level fall below one standard deviation from the norm. Since ideation and conveying of meaning is the most logical purpose of writing, the authors consider this a very promising finding. It might suggest that teachers of the learning disabled should emphasize and reinforce these meaningful aspects of writing and de-emphasize the more mechanical aspects until a later date so that students can build confidence and positive attitudes toward writing activities before the more difficult and less meaningful activities are introduced.

The data indicate that learning disabled students do, in fact, perform significantly less effectively on some of the more mechanical, conventional aspects of written expression - spelling, word usage, and style. Implications for teaching are difficult. The one consistent finding in the literature regarding writing instruction of normal students is that formal, traditional, rule-based grammar instruction does not improve the ability to write (LeFevre, 1970; Braddock et al., 1963). This finding may be even more significant for teachers of the learning disabled than for those of the nondisabled. Until otherwise proven, meaningful writing experiences with immediate, reasonable, and knowledgeable feedback still seem to offer the most effective method of improving mechanical, conventional knowledge of the writing process without interfering with and stifling the all-important ability to "get across" in writing what the student intends to communicate.

It is interesting to note that the three subtests on which the learning disabled students performed less well than their nondisabled peers use a contrived format. An interesting question is posed as to whether or not results from a contrived format provide information as significant to writing effectiveness as actual examples of the students' attempts to convey meaning through writing. Are learning disabled children less able to take contrived tests? This question, although interesting, can only be answered by comparing mechanical abilities in both spontaneous and contrived formats.

The LD students' poor performance on mechanical, contrived assessment tasks also suggests the possibility that the more natural writing activities should be employed more frequently by learning disability teachers. The consistent use of worksheet pages where the student is asked to correct mechanical errors of a "given" sentence or paragraph may not only be the most difficult for the LD student but also the least meaningful. The generalization of these synthetic activities to the actual written products of students is an area begging for more research with all students. A far more pertinent activity than the consistent use of worksheet activities might be the gradual training of the LD students to proofread and correct their own written compositions. This would increase the likelihood that (1) the students know the words and ideas involved in the written expression activities (as would less likely be the case with teacher-made or company-made sentences), and (2) generalization of mechanical tasks to the students' own writing is inherent in the activity and does not have to be presumed. Clearly, the learning disability specialist should attend more to building LD pupils' written expression abilities. 
The limitations of this preliminary study included the inability to obtain specific IQ scores for the normal groups, and the use of only suburban school districts. Replication is needed with these limitations in mind. Further studies should examine in greater detail LD students' syntactic, mechanical, and productive abilities as demonstrated in actual written products; the comparative rate and degree of development of learning disabled individuals and their nondisabled peers; the relationship between purpose of writing and writing performance; the differences between the composing processes of learning disabled writers and those who are considered "good" writers; learning disabled children's test-taking skills; the homogeneity of those identified as learning disabled in relation to writing abilities; and the effectiveness of various interventions (or noninterventions) to improve learning disabled children's ability to express themselves in writing.

\section{REFERENCES}

Anastasiow, N. Review of the Picture Story Language Test. In O.K. Buros(Ed.), Seventh mental measurement yearbook. Highland Park, $\mathrm{NJ}$ : Cryphon, 1972.

Braddock, R., Lloyd-Jones, R., \& Schoer, L. Research in written composition. Champaign, IL: National Council of Teachers of English, 1963.

Britton, J.N. The composing processes and the functions of writing. In C. Cooper \& L. Odell (Eds.), Research on composing: Points of departure. Urbana, IL: National Council of Teachers of English, 1978.

Deno, S.L., Mirkin, P.K., \& Marston, D. Relationships among simple measures of written expression and performance on standardized achievement tests. Institute for Research on Learning Disabilities. Research Report No. 22. University of Minnesota, 1980.

Emig, J. Hand, eye, brain: Some 'basics' in the writing process. In C. Cooper \& L. Odell (Eds.), Research on composing: Points of departure. Urbana, IL: National Council of Teachers of English, 1978.

Hammill, D., \& Bartel, N. Teaching children with learning and behavior problems. Boston: Allyn and Bacon, 1978.

Hammill, D., \& Larsen, S. Test of Written Language. Austin, TX: Pro-Ed., 1978.

Hermreck, L. A comparison of the written language of learning disabled and non-learning disabled elementary children using the Inventory of Written Expression and Spelling. Unpublished manuscript, University of Kansas, 1979.

Hunt, K. Grammatical structure written at three grade levels. National Council of Teachers of English, Research Report No. 3. Urbana, IL: National Council of Teachers of English, 1965.

Hunt, K. Recent measures in syntactic development. Elementary English, 1966, 43, 732-739.

Hunt, K. Early blooming and late blooming syntactic structures. In C. Cooper \& L. Odell (Eds.), Evaluating writing: Describing, measuring, judging. Urbana, IL: National Council of Teachers of English, 1977.

LeFevre, C. Linguistics, English and the language arts. Boston: Allyn \& Bacon, 1970.

Lerner, J.W. Children with learning disabilities (2nd ed.). Boston: Houghton Mifflin Co., 1976.

Loban, W.D. Language ability: Grades ten, eleven, and twelve. Final Report, EDO14477, 1967.

Loban, W.D. Language ability: Grades seven, eight, and nine. Washington, DC: Superintendent of Documents, U.S. Government Printing Office, 1966.

Loban, W.D. The language of elementary school children. Champaign, IL: National Council of Teachers of English, 1963.

Kansas Institute of Research on Learning Disabilities. Research Report No. 13. University of Kansas, 1980.

Myklebust, H.R. Development and disorders of written language (Volume One): Picture Story Language Test. New York: Grune and Stratton, 1965.

Myklebust, H.R. Development and disorders of written language (Volume Two): Studies of normal and exceptional children. New York: Grune and Stratton, 1973.

Petty, W. The writing of young children. In C. Cooper \& L. Odell (Eds.), Research on composing: Points of departure. Urbana, IL: National Council of Teachers of English, 1978.

Poteet, J.A. Characteristics of written expression of learning disabled and non-learning disabled elementary school students (ERIC Document ED159-830). Muncie, IN: Ball State University, 1978. (a)

Poteet, J.A. The Inventory of Written Expression and Spelling. Muncie, IN: Ball State University, 1978. (b)

Special thanks are expressed to Mary Cronin, Rebecca Edmiaston, Jo Herold, and Mary Campbell for their assistance. 